\title{
Analysis on the Spatial Correlation of Industrial Structure Supererogation in China
}

\author{
Fanchao Kong \\ School of Statistics \\ Shandong University of Finance and Economics \\ Ji'nan, China
}

\begin{abstract}
Taking 31 provinces and cities in china from 1998 to 2013 as research sample, we study the effect factors on the Spatial Correlation of Industrial Structure Supererogation in China by using the QAP method, based on the measure of Industrial Structure Supererogation. We find that the spatial correlation network of industrial structure supererogation has spillover effect. The neighbor of geographical location, the similar structure of government expenditure, investment consumption, technology change, foreign direct investment have significant positive effect on spatial correlation, while the human capital's role is just opposite. Besides, the similar of relation matrix can explain $49.4 \%$ of spatial correlation, which have obviously spatial linkage effect.
\end{abstract}

Keywords-Industrial Structure Supererogation; Spatial Correlation network; QAP method

\section{INTRODUCTION}

The upgrading of industrial structure is the essential requirement of promoting economic growth and changing the mode of economic development (Syrquin and Chenery, 1989), which requires improving the efficiency of resource allocation and guiding industrial structure to the direction of heightening. The industrial Structure Supererogation is the evolution of the industrial structure from simple to complex, low to high.

The optimization of industrial structure continues to improve in china in recent years. But the phenomenon of industry tide, excess capacity and economic fluctuations are still serious. The regional industrial structure level difference is an important factor of affecting the quality of China's economic development (Lan and Chen, 2013). Promoting the upgrading of industrial structure has become a necessary condition for the healthy development of China's economy.

\section{LITERATURE REVIEW}

The upgrading of industrial structure is affected by factors, such as urbanization, FDI, per capita GDP, technological innovation, human capital, marketization and others(Zhang, and Zhang, 2015; Gao and Chen, 2010). In recent years, with the development of spatial econometrics, researchers began to pay attention to the spatial correlation characteristics in the process of the development of industrial structure. Many literatures show that the Industrial Structure Supererogation of China does show spatial relevance. Due to the flow of interregional elements, the upgrading of industrial structure is often constrained by the surrounding areas ( $\mathrm{He}$ and $\mathrm{Pu}, 2010)$.
There was convergence in the process of industrial restructuring and upgrading in China (Li, 2006). Gao and Chen (2010) established the spatial lag model to analyze the spatial correlation of China's industrial structure, and found that there was significant spatial dependence in the development of industrial structure in China. Zhang (2015) think that the spillover effect of residents' consumption, government consumption and energy investment are obvious. Besides, the Capital investment, FDI, technology, energy investment and urbanization can promote the upgrading of industrial structure.

Spatial mechanism has become an important factor in the study of upgrading industrial structure. The above literature also has some limitations: First, most of literature ignore the fact that Influencing factors may have regional associations. Second, it is difficult to accurately reveal the inherent relationship between "relational data". Based on "relational data", we will analyze the influencing factors of China's Industrial Structure Supererogation by using QAP method.

\section{VARIABLE, MethodOlOGY AND DATA}

Social network approach has become a new research paradigm. It has been applied to sociology, management, economics and other fields. Such as Schiavo et al (2010), Cassi et al (2012).

\section{A. Variable}

The first step is to build a spatial association of Industrial Structure Supererogation in the QAP method. In this paper, we use (modified) gravity model to determine the spatial network relationship. Form as shown in equation (1):

$$
y_{i j}=k_{i j} \frac{\sqrt[3]{I_{i} T_{i} g_{i}} \sqrt[3]{I_{j} T_{j} g_{j}}}{D_{i j}{ }^{2}}, \quad k_{i j}=\frac{I_{i}}{I_{i}+I_{j}}
$$

$y_{i j}$ represents the gravity between the provinces $i$ and $j$. $I_{i}\left(I_{j}\right), T_{i}\left(T_{j}\right), g_{i}\left(g_{j}\right)$ represents the index of Industrial Structure Supererogation, TFP and actual per capita GDP. $D_{i j}$ represents the geographical distance between provinces $i$ and $j$. 
The pattern of the index of Industrial Structure Supererogation is given by formula (2):

$$
I_{i t}=\sum_{n=1}^{N} r_{\mathrm{int}} L_{\mathrm{int}}
$$

$r_{\text {int }}$ represents the proportion of the added value of the $n$-th industrial sector in $i$ province, $L_{\text {int }}$ represents the Labor productivity. The share of department with high labor productivity increases, the greater the index.

\section{B. Methodology and Data}

One of the assumptions of the classical metrological model is that independent variables are independent and there is no high linear correlation. The data used in this paper belong to relational data, which may be highly correlated. The traditional method does not apply to the analysis of relational data. For the relational data, We introduce the method of QAP method in the social network analysis.

Unlike traditional test methods, QAP that based on the permutation test is a nonparametric test. It does not require the overall distribution and the assumption that the variables are independent of each other. The test results are more reliable and robust (Liu,2014).

The model is specified as follows:

$$
R=f(S, T c, L c, O c, K c, G c, P c, U c, I c)
$$

Where the spatial relationship of Industrial Structure Supererogation $R$ is the explanatory variable, explanatory variables consists of nine determinants. The nine characteristics measure Spatial geography adjacency ( $S$, 0-1 matrix), technological progress ( $T c$, similarity of technical change index), human capital structure ( $L c$, similarity of the ratio of college staff above), trade liberalization ( $O c$, similarity of the ratio of total imports and exports to the corresponding regional GDP), capital formation ( $K c$, similarity of the ratio of gross Capital formation to GDP), level of economic development ( $P C$, similarity of the per capita GDP), government expenditure ( $G c$, similarity of the ratio of government expenditure to GDP), FDI ( $I c$, similarity of the percentage of FDI in fixed assets investment) and urbanization ( $U c$, similarity of the ratio of urban population).

Our data used in this paper originate from the China Statistical Yearbook and the China Statistical Database on Economic and Social Development.

\section{EMPIRICAL RESULTS}

Based on the QAP method, This part analyze the influencing factors of Spatial Correlation of Industrial Structure Supererogation in China.

\section{A. QAP Correlation Analysis}

The idea of QAP correlation analysis is to replace the rows and columns of the matrix at the same time, and then calculate the correlation coefficient between the matrix and the pattern matrix.

With UCINET, according to the QAP correlation analysis method, we test the correlation between the matrix $R$ and the explanatory variable relation matrix. "Table I" presents the test results.

TABLE I. RESULTS OF CORRELATION COEFFICIENT TEST

\begin{tabular}{|c|l|l|l|l|}
\hline variable & $\begin{array}{c}\text { Actual } \\
\text { coefficient }\end{array}$ & Significance & Prop>= 0 & Prop<= 0 \\
\hline $\boldsymbol{S}$ & 0.608 & 0.000 & 0.000 & 1.000 \\
\hline $\boldsymbol{c} \boldsymbol{c}$ & -0.072 & 0.034 & 0.034 & 0.975 \\
\hline $\boldsymbol{c}$ & 0.108 & 0.007 & 0.007 & 0.995 \\
\hline $\boldsymbol{G} \boldsymbol{c}$ & 0.180 & 0.000 & 0.000 & 1.000 \\
\hline $\boldsymbol{K} \boldsymbol{c}$ & 0.167 & 0.001 & 0.001 & 1.000 \\
\hline $\boldsymbol{P} \boldsymbol{T}$ & 0.062 & 0.065 & 0.065 & 0.948 \\
\hline $\boldsymbol{c} \boldsymbol{c}$ & 0.140 & 0.002 & 0.002 & 0.998 \\
\hline $\boldsymbol{U} \boldsymbol{c}$ & 0.010 & 0.416 & 0.416 & 0.636 \\
\hline
\end{tabular}

The correlation coefficients of the relation matrix $R$ and the independent relation matrix $(S, T c, L c, K c, G c, I c)$ are $0.608,0.140,-0.072,0.180,0.167,0.108$, which are significant at the $5 \%$ level. In contrast, the correlation coefficients of the matrix $R$ and matrix $(P c, O c, U c$ )are not significant.

\section{B. QAP Regression Analysis}

We further measure the correlation relationship between the independent variable relational matrices. The results show that the relational matrices exit significant multicollinearity.

The traditional measurement model exposes some limitations. To solve this problem, we attempts to study the relationship between the relational matrices by QAP regression analysis. The regression results are shown in "Table II".

TABLE II. ESTIMATION RESULTS OF QAP REGRESSION

\begin{tabular}{|c|l|l|l|l|l|}
\hline independent & $\begin{array}{c}\text { Un- } \\
\text { stdized } \\
\text { coefficient }\end{array}$ & $\begin{array}{c}\text { stdized } \\
\text { coefficient }\end{array}$ & significance & PAL & PAS \\
\hline intercept & -0.009 & 0.000 & - & - & - \\
\hline $\boldsymbol{G} \boldsymbol{c}$ & 0.101 & 0.111 & 0.000 & 0.000 & 1.000 \\
\hline $\boldsymbol{L} \boldsymbol{c}$ & -0.018 & -0.020 & 0.268 & 0.732 & 0.268 \\
\hline $\boldsymbol{c} \boldsymbol{S}$ & 0.026 & 0.030 & 0.072 & 0.072 & 0.928 \\
\hline $\boldsymbol{K} \boldsymbol{c}$ & 0.688 & 0.579 & 0.000 & 0.000 & 1.000 \\
\hline $\boldsymbol{T} \boldsymbol{c}$ & 0.087 & 0.102 & 0.001 & 0.001 & 1.000 \\
\hline $\boldsymbol{T}$ & 0.039 & 0.046 & 0.071 & 0.071 & 0.929 \\
\hline
\end{tabular}

The results show the relational matrices can explain $49.4 \%$ of the Spatial Correlation of Industrial Structure Supererogation in China. In general, the neighbor of geographical location, the similar structure of government expenditure, investment consumption, technology change, foreign direct investment have significant positive effect on spatial correlation. There is a negative relation between human capital and spatial correlation of Industrial Structure Supererogation. 


\section{CONCLUSION}

Our results suggest that regional spatial effects are important to consider. Relevant departments should clarify the characteristics of regional industrial structure, taking into account its spatial effects, formulate policies that are coordinated with spatial correlation characteristics, and use the space transfer mechanism to promote the development of industrial structure. In addition, we should also stabilize the government consumption expenditure, rationalize the consumption structure, to achieve effective adjustment of social demand structure objectives. Third, optimize the capital investment structure, encourage enterprises to carry out technological innovation, optimize the direction of foreign investment.

\section{REFERENCES}

[1] M. Syrquin and H. Chenery. "Three Decades of Industrialization," The World Bank Economic Review, vol. 2, pp. 145-181, 1989.

[2] Q. X. Lan, and C. F. Chen. "Does New-type Urbanization Promote the Upgrading of Industrial Structure? - Spatial Econometric Research Based on china's Provincial Panel Data," Journal of Finance and Economics, vol. 12, pp. 57-71, 2013.

[3] C. J. Zhang, and Z. Y. Zhang. "Analysis on Influence Factors of China's Provincial Industrial Structure Upgrading from a Spatial Econometrics Perspective," Statistical Research, vol. 10, pp. 32-37, 2015.

[4] Y. D. Gao, and X. Chen. "Spatial econometric analysis of industrial structure of Chinese provinces," Systems Engineering Theory and Practice, vol. 6, pp. 993-1001, 2010.

[5] Y. M. He, and Y.X. Pu, J. C. Wang, G. Chen, and J.S. Ma. "Spatial temporal Dynamics of Industrial Structure with Markov Chains Approach in Sichuan Province," China Population, Resources and Environment, vol. 4, pp. 68-75, 2011.

[6] J. H. Li. "The Evolving Path, Convergence and Pattern of Space Gather of Industry Structure in China," Finance and Trade Research, vol. 2, pp. 7-16, 2006.

[7] S. Schiavo, J. Reyes, and G. Fagiolo. "International trade and financial integration: a weighted network analysis," Quantitative Finance, vol. 4, pp. 389-399, 2010.

[8] L. Cassi, A. Morrison, and A. L. J Ter Wal. "The Evolution of Trade and Scientific Collaboration Networks in the Global Wine Sector: A Longitudinal Study Using Network Analysis," Economic Geography, vol. 3, pp. 311-334, 2012.

[9] J. Liu. Lectures on Whole Network Approach. Truth and Wisdom Press, 2014. 